\title{
Companies' Internal Factors and Stock Liquidity: Evidence from the Baltic Markets
}

\author{
Rasa Norvaišiene் ${ }^{1}$, Jurgita Stankevičienè ${ }^{2},{ }^{1,2}$ Kaunas University of Technology
}

\begin{abstract}
The purpose of this paper is to investigate which internal factors of companies are most affecting stock liquidity in the markets of the Baltic countries. The authors of the paper investigated the dependence between the stock liquidity of Lithuanian, Latvian and Estonian companies and the companylevel factors, such as size of a company, return on assets, liquidity of assets, financial leverage, profit/loss.

The research evidenced that the internal factors significantly impacted stock liquidity in the Baltic markets during the entire investigated period of $2005-2012$, however this impact was less significant during the crisis and post-crisis period.
\end{abstract}

Keywords-Baltic stock markets, corporate financial ratios, stock liquidity.

\section{INTRODUCTION}

The significant impact on the decision about investmentattractiveness of a stock is made not only by expected return, stability of a company, openness to investors, but by the stock liquidity as well. If other conditions are equal, investors prefer the liquid stock and in case of an illiquid stock they require certain bonuses thus making liquidity a risk factor.

The definition of the stock liquidity includes several important aspects. Some authors emphasize the pace of transactions [10], [16], [21] arguing that liquidity is the ability to make a transaction quickly and without a negative impact on the price (or with minor price change). Other authors describe the liquidity as low transaction costs or as high activity of transactions. Shwartz and Francioni propose that the stock liquidity may be treated as the frequency of stock trading in a market [24]. Generalization of these considerations suggests that the stock liquidity is the ability to buy or sell a stock quickly and in a high-volume without any significant impact on price and without incurring high transaction costs.

Company-level factors affect not only the return on investments, but also the stock liquidity which is an important factor to an investor when assessing a stock. Since under the same economic conditions, the stock liquidity of individual companies is different, the question arises: what factors of a company have bigger impact on this? Many factors affect companies' stock liquidity, e.g., industrial sector development patterns [18], [25], volatility and holistic evaluation of companies' stock [23]. The importance of ownership structure to the stock liquidity is emphasized in studies of some scientists [3], [6]. The impact of the size of a company on the stock liquidity is evidenced by the research results of other scientists [8], [14], [15], [17]. Chordia et al. analysed the relationship between the size of a company, the stock price volatility and stock liquidity and concluded that under other conditions being un-changed, the liquidity of smaller companies is more correlative with stock price movements than that of larger companies. The positive relationship between the size of a company and its stock liquidity was also confirmed by other scientists [14], [15], [17].

Various authors [14], [15] have shown that a significant impact on stock liquidity is made by company's policy of information disclosure to investors. Heflin et al. concluded that the quality of information disclosure reduces information asymmetry between the investors and increases their ability to carry out trade effectively anytime and at a reasonable cost [14]. Thus, both the individual stock liquidity and the liquidity of all market are increased. The same conclusions were made also by Jain et al. who investigated the impact of disclosed information on the stock liquidity [15].

A number of researchers analysed the interaction of the stock liquidity and the capital structure of a company. Lipson $\&$ Mortal found that the stock of companies with lower leverage ratio is more liquid [20]. Lesmond et al. settled the similar findings studying the relationship between the capital structure of companies and liquidity of their stock [19]. These authors found that the companies with reducing leverage faced a statistically significant increase of price and trading volume and reduction of variability. The increased leverage creates increased information asymmetries and thus increases the costs of stock trade, which results in decreasing liquidity of a stock. The research results of Khediri and Daadaa evidenced that the stock trading activity of companies with higher leverage is low [17]. Meanwhile, other scientists conducted a research and found that the increasing company's leverage increases its stock liquidity, as the debt encourages managers of a company make better investment decisions, at the same time reducing costs of agency between managers and investors and increasing the stock liquidity as a result [11].

Another important factor affecting the stock liquidity is the liquidity of company's assets. The results of the research by Gopalan, Kadan \& Pevzner evidenced that the significant positive relationship exists among the liquidity of assets and the liquidity of a stock. The authors also found that the liquidity of assets has a greater positive impact on the stock liquidity in case of companies with lower growth potential, financially constrained companies and poorly managed companies. It was also observed that there is a stronger relationship in case of small companies and companies with a higher than the average probability of default [13].

Choi \& Cook found that the stock liquidity is significantly impacted by short-term liabilities to assets ratio, other liabilities to assets ratio, liquid assets to total assets ratio, 
amount of assets, market to book value of assets ratio, return on equity, growth of assets and sales [7]. Other scientists also examined the impact of companies' financial ratios on the stock liquidity and found that the stock liquidity of individual companies is influenced by profit before interest and taxes to assets ratio, market to book value of assets ratio, $R \& D$ expenditures to assets ratio [20].

The results of the research evidence that the company-level factors have a significant impact on the stock liquidity; however, both, the set of indicators and the level of the impact are quite different in different countries. Moreover, most of empirical studies have been carried out in developed stock markets (due to better availability of information), though some researchers have tried to study the developing stock markets like Malaysia or Indonesia as well. However the factors influencing stock liquidity in the Baltic markets have not been researched so far.

The purpose of this paper is to assess the impact of company-level factors (corporate financial ratios) on the stock liquidity of the Baltic companies.

\section{RESEARCH METHODS}

In order to explore the relationship of the Baltic stock liquidity and the company-level factors, the two-part empirical research was carried out. For this purpose 32 non-financial companies belonging to various sectors of economic activity were selected out of 79 companies listed in the Nasdaq OMX Baltic. The research covers the period of $2005-2012$. In the first part of the research, the stock liquidity of the Baltic companies and its changes during the period of 2005-2012 were analysed. In the second part, the correlation and multivariate regression analysis was performed in order to establish the impact of the company-level factors on the stock liquidity. In order to assess the impact of the financial crisis on the change of the set of factors influencing the stock liquidity, the research period was divided into two sub-periods: the period of economic growth which covers $2005-2007$ and the period of crisis and post-crisis which covers $2008-2012$.

In the research, the following independent variables that characterize the company-level factors were used:

1) size of a company $S$ (company's asset value);

2) financial leverage $F L$ (debt / equity);

3) ratio describing liquidity of assets - current solvency ratio CSR (current assets / current liabilities);

4) return on assets ROA (net profit / total assets);

5) profit or loss $P$ (net profit or net loss).

The annual financial indicators of the companies were used in this research. In order to avoid predominance of profit or loss with a large deviation and distortion of the results, the initial data were standardized by subtracting the time-series average and dividing by the variance.

In order to establish the interaction of the company-level factors and the stock liquidity, the Amihud's Illiquidity ratio (ILLIQ) was selected as an indicator of the stock liquidity. This indicator was used by a considerable part of the researchers who investigated the determinants of the stock liquidity changes, also the interaction of the stock liquidity and the return on stock [1], [4], [5], [9], [12], [21]. This liquidity measure is based on daily returns and trading volume. For every stock and for every year ILLIQ was calculated as in:

$$
\operatorname{ILLIQ}_{i, t}=\frac{1}{N_{i t}} \sqrt{\frac{\left|R_{i, j}\right|}{V O L_{i, j} \times P_{i, j-1}}},
$$

where

$N_{i, t} \quad$ is the number of trading days for stock $i$ during year $t$;

$R_{i, j} \quad$ is the return on stock $i$ on day $j$;

$V O L_{i, j}$ is trading volume of stock $i$ on day $j$;

$P_{i, j-1}$ is the closing price of stock $i$ on day $j-1$.

This measure is defined only for positive trading volume days. ILLIQ evaluates how much stock prices change reacting to the volume of trade. Low ILLIQ of a stock means that the price changes insignificantly considering the trading volume and this stock is liquid.

In the regression analysis, we estimate the following equations:

$$
\begin{aligned}
I L L I Q_{i, t}=\alpha & +\beta_{1} \ln \left(S_{i t}\right)+\beta_{2} F L_{i t}+\beta_{3} C S R_{i t}+ \\
& +\beta_{4} R O A_{i t}+\beta_{5} P_{i t}+\varepsilon_{i, t},
\end{aligned}
$$

where

$S_{i t} \quad$ is the size of a company $i$ on year $t$;

$F L_{i t}$ is the financial leverage of a company $i$ on year $t$;

CSRit is the current solvency ratio of a company $i$ on year $t$;

$R O A_{i t}$ is the return on assets of a company $i$ on year $t$;

$P_{i t} \quad$ is the net profit or loss of a company $i$ on year $t$.

\section{CHANGES OF STOCK LIQUIDITY IN THE BALTIC MARKETS DURING THE PERIOD OF 2005 - 2012}

The analysis of changes in one of the indicators characterizing stock liquidity, the number of transactions in the Baltic stock markets evidenced that the number of transactions considerably increased during the period of 2005 - 2007 (growth rate was as high as $78 \%$ ); however in 2008, this number decreased by $17.5 \%$ (see Fig. 1).

Especially significant decrease (i.e., $46 \%$ ) of the number of transactions in 2008 was experienced in the Estonian market, while at the same time in Lithuania activity of investors was higher than in the previous years (the number of transactions increased by $1.7 \%$ ). In 2009, investors were more active in both Lithuanian and Estonian market if compared to 2008, while the number of transactions in the Latvian market continued to decline. In 2010, the Estonian market experienced optimistic trends and the number of transactions increased by 16.5 thousands (19.5\%). However, since 2011, the activity of investors in the Estonian market began to decrease and only 52.4 thousands of transactions were made in 2012 (in comparison to 101.3 thousands of transactions made in 2010). The number of transactions in the Lithuanian market started to decrease already in 2010, and only 65.7 thousands of transactions were made during 2012; this number was even by $70.5 \%$ less than in 2010 . 


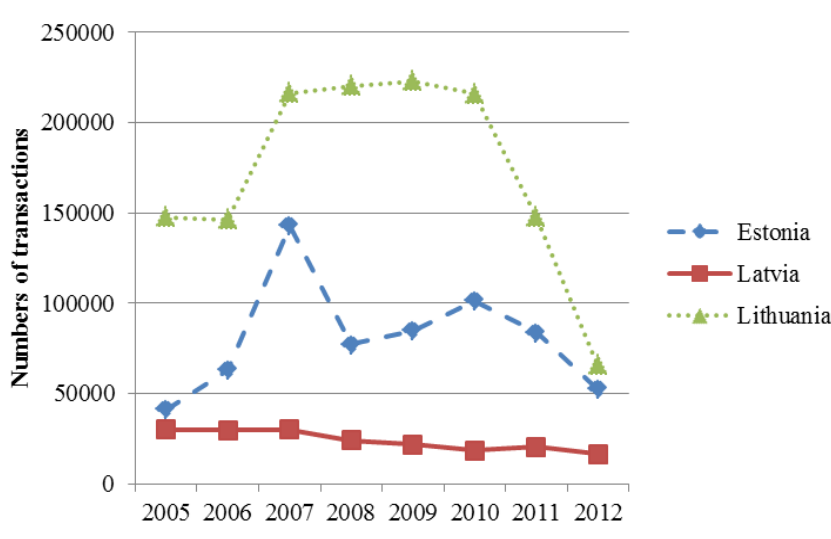

Fig. 1. Change in the number of transactions in the Baltic stock markets during the period of $2005-2012$.

The record growth of the turnover was observed in the Estonian stock market in 2007, when the turnover amounted to 1526 million euro and it was almost twice higher as compared to 2006 (see Fig. 2). However the stock turnover in the Estonian market constantly declined during the period of $2008-2012$ and amounted to only 136.4 million euro in 2012; this amount was as much as $91 \%$ lower than in 2007. The largest turnover in the Lithuanian stock market (1607 million euro) was in 2006. However, since 2007, the drop of the turnover in this market has occurred and in 2012, the turnover in the Lithuanian stock market amounted to only 129.1 million euro (i.e., decreased by $92 \%$ since 2006). Significant drop of the turnover in the Latvian stock market occurred both, in 2008 (71\%) and in 2009 (51\%). Meanwhile in 2010 and 2011, the stock of the Latvian companies has attracted more interest from the investors, and the turnover in this stock market was 2.7 times higher in 2011 compared to 2009. In 2012, the stock turnover in Latvia decreased significantly like in other Baltic countries due to notably diminished activity of the investors.

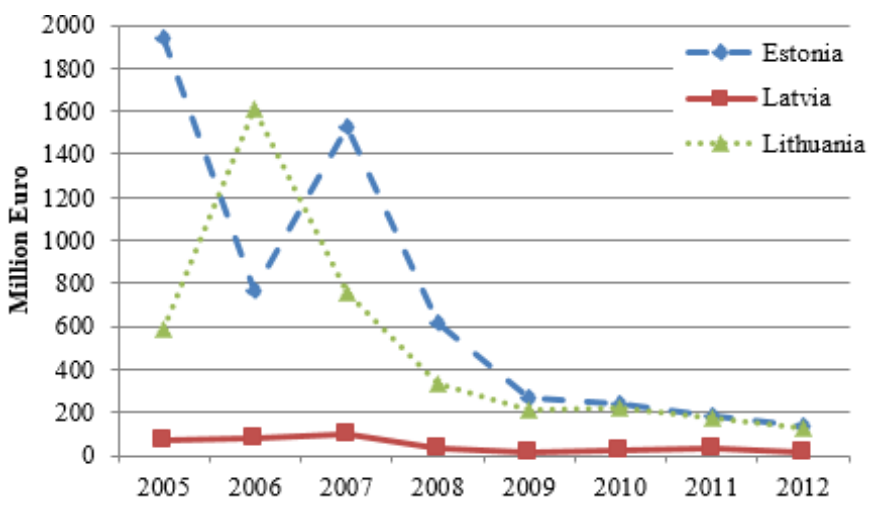

Fig. 2. Change in the trade volume in the Baltic stock markets during the period of $2005-2012$.

The investigation of the level of the stock illiquidity indicator in the Baltic markets evidenced that the stock of Latvian companies distinguished by the largest illiquidity during all the research period (see Fig. 2). In this country, the crisis had a particularly significant impact on the reduction in the level of the stock liquidity as well: the illiquidity indicator ILLIQ in Latvia increased by 1.7 times (from 0.037 to 0.065 ) in 2008 as compared to the years 2007 and 2009 when this indicator exceeded the pre-crisis level even 2.2 times. Although in later years the stock illiquidity indicator of Latvian companies decreased, it remained relatively high and well above the pre-crisis level.

The crisis has had a significant impact on the liquidity of the stock in the Lithuanian and Estonian markets as well (see Fig. 3). Especially high jump of the illiquidity may be observed in 2008, when the ILLIQ indicator in the Lithuanian market increased up to 0.022 (it was 0.014 in 2007) and in the Estonian market it increased from 0.017 up to 0.027 during the same period. However, already in 2009, the situation in the Baltic stock markets began to improve; the stock prices did not reacted so sensitively to the turnover changes, thus the stock liquidity increased and in 2010 it reached the pre-crisis level in both Estonia and Lithuania.

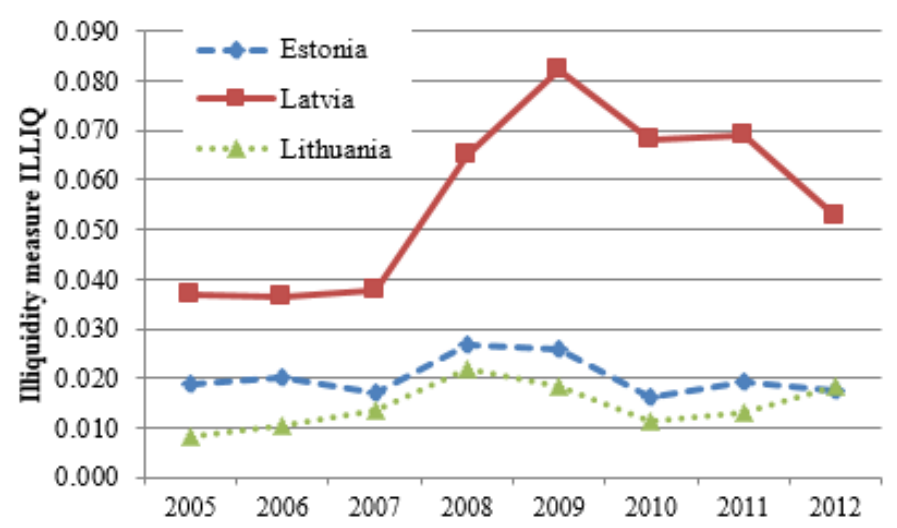

Fig. 3. Change in the illiquidity indicator in the Baltic countries during the period of $2005-2012$

In 2011, the ILLIQ indicator increased in all Baltic countries, therefore the stock liquidity decreased.

During the period of 2005-2011, the stock of the Lithuanian companies was distinguished by the highest liquidity in the Baltic markets. However in 2012, the liquidity decreased in the Lithuanian market and more favourable situation emerged in Estonia, therefore the stock liquidity of the Estonian companies, although slightly, but exceeded the stock liquidity of Lithuanian companies.

\section{IV.THE RELATIONSHIP OF INTERNAL FACTORS OF COMPANIES AND STOCK LIQUIDITY IN THE BALTIC MARKETS DURING THE PERIOD OF 2005 - 2012}

In order to investigate the relationship of the liquidity with the indicators describing internal factors of the companies the correlation analysis was performed. The $p$-value was used to verify the reliability of the observed correlation. Only the statistically significant correlation coefficients at the significance level of 0.05 are presented here (i.e., the correlation between the ratios is considered to be reliable and significant when the $p$-value <0.05). Other correlation coefficients (not presented in the tables), were statistically insignificant, because the derived $p$-values exceeded the established significance level. The results of the correlation analysis are presented in Table I and Table II. 
TABLE I

THE CORRELATION OF STOCK LIQUIDITY AND INTERNAL FACTORS OF THE COMPANIES DURING THE PERIOD OF 2005 - 2007

\begin{tabular}{|l|c|c|c|c|c|}
\hline Country & S & FL & CSR & P & ROA \\
\hline Lithuania & -0.330 & 0.442 & -0.647 & -0.598 & -0.381 \\
\hline Latvia & - & - & - & - & - \\
\hline Estonia & -0.752 & - & - & -0.780 & - \\
\hline
\end{tabular}

During the period of 2005-2007, a weak negative correlation between the illiquidity indicator ILLIQ and the size of a company, the ILLIQ and the return on assets, as well as a medium negative correlation between the ILLIQ and the current solvency ratio and the ILLIQ and the size of profit was established in the Lithuanian market; this indicates that higher earned profits of a company, more efficiently managed assets and higher current solvency reduce the stock price reaction to the change in the volume of trade and thus increases the stock liquidity. The capital structure also was related to the stock liquidity of the Lithuanian companies during the investigated period as the stock of the companies with higher leverage was distinguished by higher ILLIQ indicator. That means that the companies which had lower level of debt, had more liquid stock.

The research of the stock liquidity correlation with the corporate financial ratios in the Latvian market did not evidence any significant correlations during the period of $2005-2007$.

Meanwhile, in the Estonian market a strong negative correlation between the size of the profit and the ILLIQ, as well as a strong negative correlation between the size of a company and the ILLIQ was established during the research period, i.e., the stock of larger, as well as earning higher profits Estonian companies was more liquid.

The investigation of the correlation between the stock liquidity and the company-level indicators in the Lithuanian market during the period of 2008-2012 evidenced that the majority of the investigated indicators correlated with the illiquidity indicator ILLIQ; a weak negative correlation was found between the ILLIQ and the size of a company, the current solvency ratio, the return on assets, meanwhile a medium negative correlation was observed between the ILLIQ and the size of profit. A weak positive correlation was observed between the financial leverage and the ILLIQ. Thus the stock of larger Lithuanian companies characterized by higher current solvency and higher profit rates but having a lower financial leverage, was more liquid during the period of $2008-2012$.

A negative correlation between the ILLIQ and the size of profit, as well as between the ILLIQ and the return on assets was also observed in the Latvian companies during the analysed period, but this correlation was weak. A medium positive correlation between the financial leverage and the ILLIQ was evidenced in the Latvian market during the period of $2008-2012$, i.e., the stock of more indebted companies was distinguished by lower liquidity.

TABLE II

THE CORRELATION OF STOCK LIQUIDITY AND INTERNAL FACTORS OF THE COMPANIES DURING THE PERIOD OF 2008 - 2012

\begin{tabular}{|l|c|c|c|c|c|}
\hline Country & S & FL & CSR & P & ROA \\
\hline Lithuania & -0.316 & 0.256 & -0.296 & -0.534 & -0.406 \\
\hline Latvia & - & 0.360 & - & -0.364 & -0.431 \\
\hline Estonia & -0.774 & - & - & -0.408 & - \\
\hline
\end{tabular}

As during the pre-crisis period, so during the period of 2008 2012, the correlation between the stock liquidity and the size of a company as well as the size of profit was established in the Estonian market: a weak negative correlation was observed between the size of profit and the ILLIQ whereas a strong negative correlation was observed between the size of the company and the illiquidity indicator ILLIQ.

In order to assess the impact of the company-level factors on the stock liquidity in the Baltic markets, the multivariate regression analysis has been carried out. For this analysis the dependent variable was the ILLIQ indicator and the independent variables - corporate financial ratios. The main results of this analysis for different sub-periods are presented in Table III and Table IV. The following tables provide the beta coefficients of the statistically significant variables and values of the constant only when the regression equations have the coefficient of determination higher than 0.2. The multiple regression analysis evidenced that the stock liquidity of the Lithuanian companies was significantly influenced by the current solvency and the financial leverage, i.e., higher stock liquidity was determined by the higher liquidity of assets of a company and lower level of debt in the capital structure during the period of 2005-2007. Changes in these indicators explained changes of the ILLIQ by $50.3 \%$. Other indicators, i.e., the size of a company, earned profits and the return on assets have been eliminated from the regression equation due to multicolinearity.

None of the investigated company-level factors had a significant impact on the stock liquidity of the Latvian companies during the period of 2005-2007. Meanwhile, the stock liquidity in the Estonian market was significantly influenced only by the size of a company, which explained even $60.9 \%$ of change of the illiquidity indicator ILLIQ.

TABLE III

THE Results OF Multivariate REgRESSION ANALYSIS FOR THE PERIOD OF 2005 - 2007

\begin{tabular}{|l|c|c|c|c|c|c|c|}
\hline \multirow{2}{*}{ Country } & \multicolumn{5}{|c|}{ Significant variables } & \multirow{2}{*}{ Constant } \\
\cline { 2 - 7 } & S & FL & CSR & P & ROA & 7.025 \\
\hline Lithuania & - & 0.273 & -0.381 & - & - & - \\
\hline Latvia & - & - & - & - & - & - \\
\hline Estonia & -0.807 & - & - & - & - & 7.108 \\
\hline
\end{tabular}


TABLE IV

The Results of Multivariate Regression ANALYsis FOR THE PERIOD OF 2008 - 2012

\begin{tabular}{|l|c|c|c|c|c|c|c|}
\hline \multirow{2}{*}{ Country } & \multicolumn{5}{|c|}{ Significant variables } & \multirow{2}{*}{ Constant } & \multirow{2}{*}{ Coefficient of determination } \\
\cline { 2 - 7 } & S & FL & CSR & P & ROA & & 0.285 \\
\hline Lithuania & - & - & - & -0.439 & - & 7.131 & 0.259 \\
\hline Latvia & - & 0.220 & - & - & -3.004 & 8.268 & 0.518 \\
\hline Estonia & -0.593 & - & - & - & - & 14.202 & \\
\hline
\end{tabular}

It should be noted that neither size of the profit nor the return on assets had an impact on the stock liquidity in the Baltic markets during the period of $2005-2007$.

Completely different results were obtained from the research of the stock liquidity and its determinants - internal factors of the companies in the Baltic markets during the crisis and post-crisis period. The research evidenced that in all three countries, the stock liquidity was influenced by different financial ratios of the companies.

In the Lithuanian market, the stock liquidity of all tested parameters was significantly impacted only by the size of profit; i.e., companies which earned bigger profit were distinguished by higher stock liquidity during the period of $2008-2012$. However, change of the size of profit explained only $28.5 \%$ of the ILLIQ change for the Lithuanian companies. Other indicators were eliminated from the regression model.

In the Latvian market, the stock liquidity was significantly impacted only by the financial leverage and the return on assets. However, the change of these indicators explained only $25.9 \%$ of change of the ILLIQ indicator.

When investigating the dependence of the ILLIQ on the company's internal factors in the Estonian market for the period of $2008-2012$, only the size of a company was included in the regression model as a significant indicator. The change of the size of a company explained $51.8 \%$ of the ILLIQ change in this country.

It should be mentioned that the current solvency did not have any statistically significant impact on the stock liquidity in all Baltic countries during the period of 2008-2012. Moreover, the analysis evidenced that determination coefficients decreased during the period of 2008-2012 if compared to the period of $2005-2007$. This allows assuming that the influence of the internal factors of companies on the stock liquidity decreased during the crisis and post-crisis period; therefore, the fluctuations of the stock liquidity were more impacted by the external factors, which do not depend on a company itself.

\section{CONCLUSION}

The analysis of changes in the number of transactions (one of the indicators characterizing the stock liquidity) in the Baltic stock markets evidenced quite different trends. The financial crisis has resulted in significant decrease of number of transactions in the Estonian and Latvian markets in 2008. However, even larger decrease of the number of transactions in the Baltic stock markets was observed in 2011 and 2012. In 2012, 134.3 thousand transactions were made in the Baltic market and it was as much as $58 \%$ less than in the year of crisis (2008).

Together with the decreasing number of transactions and prices, the turnover in the Baltic stock markets also declined substantially: it decreased from 2596 million euro to 282 million euro per year (i.e., even by $89.1 \%$ ) during the period of 2005 - 2012.

The analysis of the level of the stock illiquidity indicator ILLIQ in the Baltic markets evidenced that the Latvian companies were distinguished by the largest illiquidity during all the investigated period. In this country, the financial crisis resulted in highly significant growth of the ILLIQ both in 2008 and in 2009. The financial crisis has also negatively affected the stock liquidity in the Estonian and Lithuanian markets, but the growth of ILLIQ has not been as rapid as in the Latvian market.

The correlation analysis of the stock illiquidity indicator and corporate financial ratios evidenced that during the period of economic growth (i.e., 2005 - 2007) stock illiquidity in the Lithuanian market correlated with all tested indicators. A weak negative correlation was observed between the ILLIQ and the size of a company, the return on assets, a medium negative correlation was observed between the ILLIQ and the liquidity of assets and the size of profit. Statistically significant correlation between the ILLIQ indicator and the analyzed financial ratios was observed in the Lithuanian stock market in crisis and post-crisis period as well; however, the correlation of the illiquidity with the company's capital structure and solvency became weaker.

During the period of 2005 - 2007, no statistically significant correlation between the stock illiquidity and the corporate financial ratios was observed in the Latvian market, whereas during the period of 2008 - 2012, a significant correlation was found between the ILLIQ and the financial leverage and the return on assets, but this correlation was weak.

In the Estonian market, a strong negative correlation was observed between the illiquidity indicator and the size of a company both during the period of 2005 - 2007 and 2008 2012 , but the correlation between the level of ILLIQ and the size of profit was strong during the period of $2005-2007$ and weakened to the medium during the crisis and post-crisis period.

The multiple regression analysis evidenced that the financial crisis caused changes of the indicators determining the stock illiquidity in the Baltic markets. The financial leverage had a statistically significant negative impact and the liquidity of assets had a statistically significant positive impact on the stock liquidity of the Lithuanian companies during the period of $2005-2007$, while during the period of $2008-$ 
2012, only the negative impact of the size of profit was statistically significant. In the Latvian market, none of the tested indicators had a significant impact on the stock liquidity during the period of $2005-2007$, while during the period of 2008 - 2012, the stock liquidity of the Latvian companies was positively affected by lower financial leverage and higher return on assets. In the Estonian market, the positive impact on the stock liquidity was made only by the company's size during all the research period.

Summing up the results of the research suggests that the corporate financial ratios significantly affected the stock liquidity in the Baltic stock markets both during the economic growth (the period of 2005 - 2007) and during the crisis and post-crisis period; however, during the period of $2008-2012$, their influence decreased.

Different relationships between the stock liquidity and companies' internal indicators in particular countries could be determined by different level of the information efficiency in the markets of these countries, as well as by different impact of macroeconomic factors on stock market liquidity. The economic changes in the Baltic countries were rather different during the research period; moreover, particular governments conducted diverse monetary policy, which, as it was shown by various scientific studies, affect the capital markets both directly and indirectly. Such a situation inevitably has a different impact on the investors' decisions. The impact of the macroeconomic factors on the stock market liquidity intensifies particularly during the economic downturn, and this impact strongly influences the less liquid stock.

\section{REFERENCES}

[1] Acharya, V. V., Pedersen, L. H., "Asset pricing with liquidity risk," Journal of Financial Economics, 2005, vol. 77, pp. 375-410. http://dx.doi.org/10.1016/j.jfineco.2004.06.007

[2] Amihud, Y.., "Illiquidity and stock returns: cross-section and time-series effects," Journal of financial markets, 2002, vol. 5, no. 1, pp. 31-56. http://dx.doi.org/10.1016/S1386-4181(01)00024-6

[3] Attig, A., Gadhoumm, Y., Lang, L. H. P., "Bid-ask spread, asymmetric information and ultimate ownership," In: EFMA Conference, Helsinki, 2003. Bekaer, G., Harvey, C. R., Lundblad, C., "Liquidity and expected returns: lessons from emerging markets," The Review of the Financial Studies 2007, vol. 20, no. 6, pp. 1783-1831. http://dx.doi.org/10.1093/rfs/hhm030

[4] Benić, V., Franić, I., "Stock Market Liquidity: Comparative Analysis of Croatian and Regional Markets," Financial Theory and Practice, 2008, vol. 32, no. 4, pp. 477-498.

[5] Brockman, P., Chung, D.Y., Perignon, C., "Commonality in liquidity: a global perspective," Journal of Financial and Quantitative Analysis, 2009, vol. 44, no. 4, pp. 851-882. http://dx.doi.org/10.1017/S0022109009990123

[6] Choi, W. G., Cook, D., "Stock Market Liquidity and the Macroeconomy: Evidence from Japan," Monetary Policy under Very Low Inflation in the Pacific Rim, NBER-EASE, National Bureau of Economic Research, 2006, vol. 15 , pp. 309-340. http://dx.doi.org/10.7208/chicago/9780226379012.003.0009

[7] Chordia, T., Shivakumar, L., Subrahmanyam, A., "Liquidity dynamics across small and large firms," Economic Notes, 2004, vol. 33, pp. 111-143.http://dx.doi.org/10.1111/j.0391-5026.2004.00127.x

[8] Fang, J., Sun, Q., Wang, C., "Illiquidity, Illiquidity Risk and Stock Returns: Evidence from Japan," In: International Symposium on Econometric Theory and Applications (SETA), 2006.

[9] Fernando, Ch. S., Herring, R. J., "Liquidity shocks, systemic risk, and market collapse: theory and application to the market for perps," Journal of Banking \& Finance, 2001, vol. 32, no. 8, pp. 1625-1635. http://dx.doi.org/10.1016/j.jbankfin.2007.11.011
[10] Frieder, L., Martell, R., "On capital structure and the liquidity of a firm's stock," [Online], Working Paper, 2006. [Accessed 27.07.2014.]. Available: http://finance.eller.arizona.edu/documents/seminars/2005-6/ LFrieder.CapStructure-Liquidity04-06.pdf

[11] Goyenko, R. Y., Holden, C. W., Trzcinka, C. A., "Do liquidity Measures Measure Liquidity?" Journal of Financial Economics, 2009, vol. 92, pp. 153-181. http://dx.doi.org/10.1016/i.jifineco.2008.06.002

[12] Gopalan, R., Kadan, O., Pevzner, M., "Asset liquidity and stock liquidity," Journal of Financial and Quantitative Analysis, vol. 1, no. 1, pp. 1-70.

[13] Heflin, F., Shaw, K. W., Wild, J. J., "Disclosure policy and market liquidity: Impact of depth quotes and order sizes," Contemporary Accounting Research, 2005, vol. 22, no. 4, pp. 829-866. http://dx.doi.org/10.1506/EETM-FALM-4KDD-9DT9

[14] Jain, P. K., Kim, J., Rezaee, Z., "Trends and determinants of market liquidity in the pre- and post- Sarbanes-Oxley act periods," In: 14th Annual Conference on Financial Economics and Accounting, 2005.

[15] Jang, J., Kang, J., Lee, Ch., "Liquidity risk and expected stock returns in Korea: a new approach," Asia-Pacific Journal of Financial Studies, 2012, vol. 41, no. 6, pp. 704-738. http://dx.doi.org/10.1111/ajfs.12003

[16] Khediri, K. B., Daadaa, W. Stock trading and capital structure in Tunisian stock exchange. Journal of Business Studies, 2011, vol. 2, no. 2, pp. 10-24.

[17] Laužikas, M., Krasauskas, A., "Impacts of sustainable structural growth on the economic performance of listed companies," Entrepreneurship and Sustainability Issues, vol. 1, no. 2, pp. 81-91.

[18] Lesmond, D. A., O Connor, P. F., Senbet, L. W., "Capital structure and equity liquidity," [Online], Robert H. Smith School Research Paper No. RHS 06-067. p. 52. [Accessed 27.07.2014.]. Available: http://ssrn.com/ abstract=1107660. http://dx.doi.org/10.2139/ssrn.1107660

[19] Lipson, M. L., Mortal, S., "Liquidity and capital structure," Journal of Financial Markets, 2005, vol. 12, pp. 611-644. http://dx.doi.org/10.1016/j.finmar.2009.04.002

[20] Naes, R., Skjeltorp, J. A. Odegaard, B. A., "Stock market liquidity and the business cycle," Journal of Finance, 2009, vol. 66, no. 1, pp. 139-176.

[21] Plerou, V., Gopikrishnan, P., Stanley, H. E., "Quantifying fluctuations in market liquidity: analysis of the bid-ask spread," Physical review, 2005, vol. 71 , no. 4 , pp. $1-8$.

[22] Prause, G., "A holistic concept for the sustainable evaluation of company shares," Entrepreneurship and Sustainability Issues, 2014, vol. 2, no. 1, pp. 37-42. http://dx.doi.org/10.9770/jesi.2014.2.1(5)

[23] Schwartz, R. A., Francioni, R., Equity markets in action. The fundamentals of liquidity, market structure and trading, John Wiley \& Sohns, Hoboken, New Jersey, 2004. p. 480.

[24] Tvaronavičienè, M., Šimelytè, A., Lace, N., "Sustainable development facets: exporting industrial sectors from inside," Journal of Security and Sustainability Issues, 2014, vol. 3, no. 4, pp. 37-44. http://dx.doi.org/10.9770/jssi.2014.3.4(4)

Rasa Norvaišienè, $D r$. of Social Science (management and administration), graduated from Kaunas University of Technology in 2000.

She is an Associated Professor with the Department of Finance, School of Economics and Business, Kaunas University of Technology (Lithuania). She has previously worked as scientific researcher, consultant, project leader.

Her scientific interests include investment management, risk management, capital structure decisions, innovation efficiency assessment.

Address: Donelaicio 20, Room 228, Kaunas, LT-44309, Lithuania;

Phone: +3707300561 ;

E-mail: rasa@norvaisiene.org

Jurgita Stankevičienė holds the MBA degree. She graduated from the Faculty of Economics and Management, Kaunas University of Technology, in 2001

She is a Lecturer with the Department of Finance, School of Economics and Business, Kaunas University of Technology (Lithuania). She has previously worked as Manager, Chief economist, Board Member of different business companies.

Her scientific interests include valuation of corporate governance and its decisions in the context of corporate value; impact of macro- and microeconomic environment on corporate value.

Address: Donelaicio 20, Room 228, Kaunas, LT-44309, Lithuania;

Phone: +3707300561 ;

Email: jurgita.stankeviciene@ktu.lt 